\title{
The Relationship Between Mental Health and
} Psychosocial Stress of Reservoir Migrants in the Middle Route of China's South-to-North Water

\section{Diversion Project (SNWDP): The Mediating Role of Social Support}

This article was published in the following Dove Press journal: Psychology Research and Behavior Management

\section{Pan $\mathrm{Ke}^{\mathrm{l}, *}$ \\ $\mathrm{Li} \mathrm{Ke} \mathbb{D i D}^{2, *}$ \\ Bing $\mathrm{Liu}^{3}$ \\ Xiang Liu $^{4}$}

'School of Public Health (SPH), Tongji Medical College, Huazhong University of Science and Technology (HUST), Wuhan, 430040, People's Republic of China; ${ }^{2}$ School of Nursing, Hubei University of Medicine, Shiyan, 442000, People's Republic of China; ${ }^{3}$ School of Public Health, Hubei University of Medicine, Shiyan, 442000, People's Republic of China; ${ }^{4}$ Health Management Center, Shiyan People's Hospital, Affiliated Hubei University of Medicine, Shiyan, 442000,

People's Republic of China

*These authors contributed equally to this work
Correspondence: Xiang Liu; Bing Liu Email liuxiangyq@sina.com; sy-Ib@I26.com
Background: South-North Water Diversion Project (SNWDP) migrants were vulnerable to developing mental health problems due to post-migration stresses and lack of social support. However, the evidence on the mental health, psychosocial stress and social support of SNWDP migrants and their interrelationships are limited and inconclusive. We aimed to explore the mechanism of influence of social support on the relationship between mental health and social psychosocial stress of SNWDP migrants.

Methods: We performed a cross-sectional analysis of the data of 983 SNWDP migrants. The mental health status, psychosocial stress and social support of the participants were evaluated by Symptom Checklist-90-Revised (SCL-90-R), Psychosocial Stress Survey for Groups (PSSG) and Social Support Rating Scale (SSRS). Multiple stepwise regression model was used to analyze the data.

Results: Among the 983 individuals, the average SCL-90-R score was 1.47, the PSSG score was 30.50, and the SSRS score was 40.30. The SCL-90-R was positively correlated with PSSG $(r=0.483, P<0.001)$ and negatively correlated with SSRS $(r=-0.257, P<0.001)$, PSSG was negatively correlated with SSRS $(r=-0.516, P<0.001)$. Multiple regression analysis showed that PSSG and SSRS had significant effects on SCL-90-R prediction and that SSRS played a partial intermediary role in SCL-90-R and PSSG (46.87\%).

Conclusion: The SNWDP migrants performed a strong correlation between social support, mental health and psychosocial stress. Social support plays a part role in mediating mental health and psychosocial stress.

Keywords: South-to-North Water Diversion Project, migrants, social support, psychosocial stress, mental health, mediating effect

\section{Introduction}

The World Migration Report (WMR) estimated that there were 244 million migrants worldwide in 2015. ${ }^{1}$ China is the largest population country in the world, and the challenges related to migration are increasing. Unlike international migrations, migrants were relocated caused by economic and engineering construction in China. ${ }^{2,3}$ The South-North Water Diversion Project (SNWDP) migrants refers to the population relocation caused by the construction of Danjiangkou water 
conservancy project in China. ${ }^{4}$ Migration epidemiology has revealed that the impact of involuntary relocation on the lives of migrants, particularly on health. ${ }^{5,6}$ The Lancet Public Health editorial states that "No public health without migrant health". 7 There were 180,000 migrants who made significant contributions to the SNWDP. Hence, the health of SNWDP migrants had attracted great attention from researchers and policy makers.

Previous studies have shown that the mental health was an important part of the health of migration. ${ }^{8-10}$ Evidence have shown that sociodemographic characteristics, physical and psychological factors, and environmental factors might influence migrants' mental health. ${ }^{11-14}$ Compared with non-migrants, migrants might not be adapted to the new environment, resulting in psychosocial stress and mental diseases. Melkie et al found that common mental disorder was high among migrants returned from the Middle East countries. ${ }^{15}$ Migrants from rural to urban areas faced psychological maladjustment and social exclusion. ${ }^{16}$ Psychosocial stress refers to an emotion reaction caused by the imbalance of objective requirements and coping ability, under the stimulation of environment, life events and other factors. ${ }^{17}$ A study revealed that psychosocial stress due to the process of migrants' adaptation and marginalization in local society. ${ }^{18}$ However, all these studies focused on the mental health and psychosocial stress of both transnational and intern migrants, while researches on SNWDP migrants were limited. Thus, exploring the mental health and psychosocial stress of SNWDP migrants is needed.

Social support was the behavior and process of providing help between members of society. ${ }^{19}$ For migrants, leaving the familiar social environment means the loss of social capital. Brazilian migrants showed have lower social support compared to local Japanese. ${ }^{18}$ Baldassar $\mathrm{L}$ et al found that migrants, as vulnerable groups in society, deserve more support from social network. ${ }^{20}$ Previous studies have shown that social support, as one of the intermediate variables affecting the physical and mental health of individuals. ${ }^{21,22}$ Nevertheless, the role of social support in the mental health and psychosocial stress of SNWDP migrants was unclear, and few studies on how these variables interact and affect mental health. Therefore, we assumed that social support affects the mental health of SNWDP migrants through psychosocial stress and acts as a mediator between the two variables.

\section{Materials and Methods}

\section{Study Design and Sample Size}

The cross-sectional study of SNWDP migrants in Shiyan, Xiangyang and Wuhan, Hubei Province, in July 2016. The inclusion criteria were as follows: 1) age greater than 15 years; 2) residence over 5 years; 3 ) informed consent. People who refused to participate in the study were excluded. The sample size calculation formula was $n=Z_{1-a / 2}^{2} p(1-p) / d^{2}, d=0.1 p$ was the permissible error, $\alpha=0.05, Z_{1-\alpha / 2}^{2}=1.96$. Literature reports that the prevalence of mental illness among Chinese adults was $17.5 \%{ }^{23}$ Thus, we assumed $p=0.175, \mathrm{n}=834$, according to formula calculation. Considering the possible sample loss, the sample was increased by $20 \%$, and $n=1000$ migrants are obtained. Of the 1000 samples, 512 (51.20\%) individuals were in Shiyan, $262(26.20 \%)$ individuals in Xiangyang, and individuals $226(22.60 \%)$ in Wuhan. Multi-stage stratified random sampling was used to select the sample. First, the sample population were divided into three categories, according to the annual per capital income were, low (lower than 30,000 RMB), medium (30000-80000 RMB) and high (80,000 RMB or more). In the above cities, three towns with SNWDP migrants were randomly selected as the primary sampling unit. Secondly, three villages with SNWDP migrants were selected as the sub-sampling units in these towns; finally, the selected subjects in the selected villages were chosen to meet the inclusion criteria. A total of 1000 questionnaires were distributed and 983 questionnaires were returned. The effective recovery rate of the questionnaire was $98.30 \%$.

\section{Ethics Approval}

Participants under the age of 18 years were approved by the ethics committee (Ethics Committee of Hubei University of Medicine) to provide informed consent on their own behalf, or if this was obtained from a parent or legal guardian. This study was conducted in accordance with the Declaration of Helsinki.

\section{Data Collection}

1.Sociodemographic characteristics included sex, age, education level, occupation, and marital status, etc.

2.The mental health of SNWDP migrants was measured by Symptom Checklist-90-Revised (SCL-90-R). ${ }^{24}$ Ninety items were included in the following 10 different psychological dimensions (somatisation, obsessive- 
compulsive, interpersonal sensitivity, depression, anxiety, hostility, phobic anxiety, paranoid ideation, psychoticism and a rest subscale). The participants selected one response from the following range of responses $(0=$ not at all; $1=$ a little bit; $2=$ moderately; $3=$ quite a bit; $4=$ extremely). The scale includes a rating item with factors including somatization (12 items), obsessive-compulsive symptoms (10 items), interpersonal sensitivity ( 9 items), depression (13 items), anxiety (10 items), hostility (6 items), horror ( 7 items), paranoia (6 items), mental symptoms (10 items), and one entry not included in any of the above factors, which is collectively referred to as additional factor. The scores of the items are added together to obtain a total score, and each factor is divided into the total number of items for that factor. The higher the score, the more severe the symptoms. The internal consistency of the questionnaire was evaluated with Cronbach's $a$ coefficient, which was calculated as 0.867 .

3. The Psychosocial Stress Survey for Groups (PSSG) questionnaire was compiled by Chinese scholar Jiang qian-jin. $^{25}$ The 44 items were included in the following five dimensions: life events (L), negative emotion (NE), positive emotion ( $\mathrm{PE})$, negative coping $(\mathrm{NC})$, and positive coping (PC). The calculation method included "Yes" obtaining a score of 1 and either "No" or "No Answer" obtaining a score of 0 ; the higher the PSSG score, the greater the individual's psychosocial stress. PSSG total score was calculated as follows $=15+2 * \mathrm{~L}+3 * \mathrm{NE}-\mathrm{PE}$ $+5 *$ NC-PC. The PSSG total score, L, NE, PE, NC, and $\mathrm{PC}$ retest reliability were $0.88,0.70,0.83,0.76,0.80$, and 0.81 , respectively.

4.The Social Support Rating Scale (SSRS) questionnaire was compiled by Chinese scholar Xiao shui-yuan. ${ }^{26}$ The Cronbach's $a$ was 0.86 . Ten items were included objective support, subjective support, and utilization of support, at 3 latitudes. The total score is the sum of the scores of 10 items; objective support is divided into the sum of the scores of the $2 \mathrm{nd}$, 6th, and 7 th items; subjective support is divided into the sum of the scores of the 1st, 3rd, 4th, and 5th items; utilization of support was divided into the sum of the scores of the 8th, 9th, and 10th items. A higher score represents more social support.

The investigators were made up of college students from Hubei University of Medicine. Face-to-face interviews with the participants were conducted for data collection. When filling out the questionnaire, the respondents were required to not be influenced by any external interference and to answer independently. If the respondents were illiterate or had little literacy, the investigator can ask the participants and fill in a questionnaire. After the respondent completed the questionnaire, it was immediately submitted to the investigator.

\section{Statistical Analysis}

Data analysis was performed using SPSS 22.0. Counting data were expressed as the frequency, Chi-square test was used for comparison between groups. Measurement data were analysed by mean standard deviation $(X \pm \mathrm{s}) . p<0.05$ was considered statistically significant. The correlation between mental health, psychosocial stress and social support was analyzed. The mediating variable was the mediator of the independent variable's influence on the dependent variable, and the independent variable has an effect on the dependent variable. According to Baron and Kenny's explanation, ${ }^{27}$ the mediator variable (Mediator) means that the causal relationship between variables (X and $\mathrm{Y}$ ) is generated by the third variable $\mathrm{M}$ (mediator variable); that is, $\mathrm{M}$ is the mediator of variables $\mathrm{X}$ and $\mathrm{Y}$. The effect of $\mathrm{X}$ on $\mathrm{Y}$ is generated in whole or in part by the variable $\mathrm{M}^{27}$ In this study, the $\mathrm{X}$ variable is psychosocial stress, the $\mathrm{Y}$ variable is mental health, and $\mathrm{M}$ is social support. The mediating effect can be determined by the linear regression method (Causal step). The specific steps are as follows: 1) the regression effect of $\mathrm{X}$ on $\mathrm{Y}$ is $\left(\mathrm{Y}=c \mathrm{X}+e_{1}\right)$ and is significant; that is, the standardized regression coefficient of $X$ is significant; 2) the regression effect of $\mathrm{X}$ on $\mathrm{M}$ is $\mathrm{M}=a \mathrm{X}+e_{2}$, and the effect of a should also be significant; and 3 ) investigation of the regression effect of $\mathrm{X}$ and $\mathrm{M}$ on $\mathrm{Y}$ is $\left(\mathrm{Y}=c^{\prime} \mathrm{X}+b \mathrm{M}+e_{3}\right)$. If the coefficient $b$ is significant and the coefficient $c^{\prime}$ is not significant, then $\mathrm{M}$ acts as a complete mediating effect. If the coefficient $b$ and the coefficient $\mathrm{c}$ are both significant, then $\mathrm{M}$ has a partial mediating effect. If the coefficient $b$ is not significant, then $\mathrm{M}$ is not a mediator of $\mathrm{X}$ and $\mathrm{Y}$ and acts only as a moderator. Based on this theory, our study analysed the intermediary role of SNWDP migrants social support on psychosocial stress and mental health through the steps of sequential testing (significance level $a=0.05$ ). The mediating effect procedure is shown in Figure 1.

\section{Results}

\section{The Characteristics of Participants}

Among the 983 SNWDP migrants, with an average age of 52.57 years, 501 individuals were male (50.96\%), and 482 individuals were female $(49.01 \%)$. There were statistically 


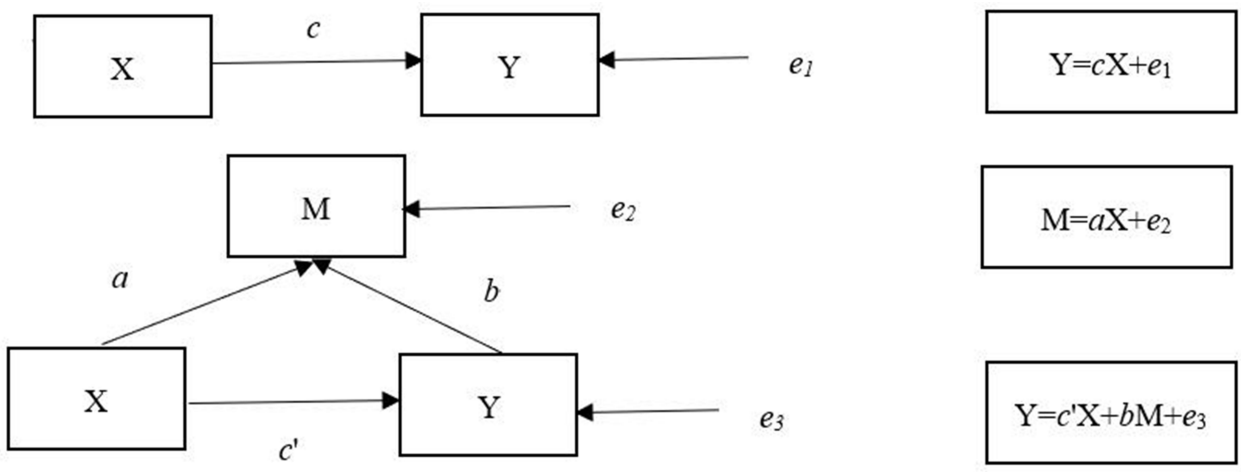

Figure I Mediating effect test procedure.

significant differences in sex with age and occupation groups. The characteristics of participants were shown in Table 1.

\section{The Status of Mental Health, Psychosocial Stress and Social Support Level of SNWDP Migrants}

The average SCL-90-R score of the SNWDP migrants was 1.47 , the PSSG score was 30.50 , and the SSRS score was 40.30 .

\section{Correlation Analysis}

The mental health of SNWDP migrants was positively correlated with psychosocial stress $(r=0.483, p<0.001)$, and negatively correlated with social support $(r=-0.257$, $p<0.001)$, psychosocial stress was negatively correlated with social support $(r=-0.516, p<0.001)$. The results are shown in Table 2.

\section{The Mediating Effect Analysis}

Given the correlation analysis only showed the mutual influence relationship between variables, and might be the result

Table I Demographic Characteristics of Participants [n (\%)]

\begin{tabular}{|c|c|c|c|c|}
\hline Characteristics & Male $(n=501)$ & Female $(n=482)$ & $\chi^{2}$ & $p$ \\
\hline $\begin{array}{l}\text { Age groups (age years) } \\
\text { 16 } \\
35 \sim \\
\geq 55\end{array}$ & $\begin{array}{c}71(14.17) \\
211(42.12) \\
219(43.7 I)\end{array}$ & $\begin{array}{c}76(15.77) \\
145(30.08) \\
261(54.15)\end{array}$ & 15.72 & 0.01 \\
\hline $\begin{array}{l}\text { Marital status } \\
\text { Married } \\
\text { Unmarried }\end{array}$ & $\begin{array}{c}63(12.57) \\
438(87.43)\end{array}$ & $\begin{array}{c}60(12.44) \\
422(87.56)\end{array}$ & 0.004 & 0.952 \\
\hline $\begin{array}{l}\text { Education status } \\
\text { Primary and lower } \\
\text { Junior middle graduate } \\
\text { High school graduate }\end{array}$ & $\begin{array}{c}245(48.90) \\
179(35.73) \\
77(15.37)\end{array}$ & $\begin{array}{c}239(49.58) \\
162(33.61) \\
81(16.81)\end{array}$ & 0.656 & 0.720 \\
\hline $\begin{array}{l}\text { Occupation } \\
\text { Farmer } \\
\text { Non-farmer }\end{array}$ & $\begin{array}{l}351(70.06) \\
150(29.94)\end{array}$ & $\begin{array}{l}307(63.69) \\
175(36.31)\end{array}$ & 4.500 & 0.034 \\
\hline $\begin{array}{l}\text { Ethnicity } \\
\text { Han } \\
\text { Minority }\end{array}$ & $\begin{array}{c}473(94.4 I) \\
28(5.59)\end{array}$ & $\begin{array}{c}467(96.89) \\
15(3.11)\end{array}$ & 3.603 & 0.058 \\
\hline $\begin{array}{l}\text { Religion } \\
\text { Yes } \\
\text { No }\end{array}$ & $\begin{array}{c}70(\mid 3.97) \\
431(86.03)\end{array}$ & $\begin{array}{c}67(13.90) \\
415(86.10)\end{array}$ & 0.001 & 0.974 \\
\hline
\end{tabular}


Table 2 Correlation Analysis of SNWDP Migrants' Mental Health, Psychosocial Stress and Social Support ( $r$ Value)

\begin{tabular}{|l|c|c|c|}
\hline Variables & SCL-90-R-Total Score & PSSG-Total Score & SSRS-Total Score \\
\hline SCL-90-R total score & $\mathrm{I}$ & $0.483^{*}$ & $-0.257^{*}$ \\
\hline PSSG-total score & $0.483^{*}$ & $\mathrm{I}$ & $-0.516^{*}$ \\
\hline SSRS-total score & $-0.257^{*}$ & $-0.516^{*}$ & $\mathrm{I}$ \\
\hline
\end{tabular}

Note: $*_{p}<0.05$.

Abbreviations: SCL-90-R, Symptom Checklist-90-Revised; PSSG, Psychosocial Stress Survey for Groups; SSRS, Social Support Rating Scale.

Table 3 Results of Mediating Effect Analysis

\begin{tabular}{|l|c|c|c|c|}
\hline Dependent Variables & Standardized Regression Equation & Standardized Coefficients (Beta) & $\boldsymbol{t}$ & $\boldsymbol{p}$-value \\
\hline First: SCL-90-R & Y=0.049X & 0.049 & 3.546 & $<0.01$ \\
\hline Second: SSRS & M=-0.023X & -0.023 & -2.763 & $<0.01$ \\
\hline Third: SCL-90-R & Y=0.193M & 0.193 & 6.150 \\
& $-0.119 X$ & -0.119 & $<0.01$ \\
& & -3.741 & $<0.01$ \\
\hline
\end{tabular}

Abbreviations: SCL-90-R, Symptom Checklist-90-Revised; PSSG, Psychosocial Stress Survey for Groups; SSRS, Social Support Rating Scale.

of variables acting together. We assumed that psychosocial stress not only directly affects mental health but also indirectly affects mental health through the mediating role of social support. Demographic variables were controlled and multivariate stepwise regression analyses were performed. First, PSSG total score was taken as the independent variable, SCL-90-R total score was used as the dependent variable for linear regression analysis. Psychosocial stress had a positive predictive effect on mental health $(\beta=0.049$, $p<0.01)$. Second, PSSG total score was divided into independent variables, and SSSR total score was divided into dependent variables. Linear regression analysis was carried out. The results showed that psychosocial stress had a negative predictive effect on social support $(\beta=-0.023$,

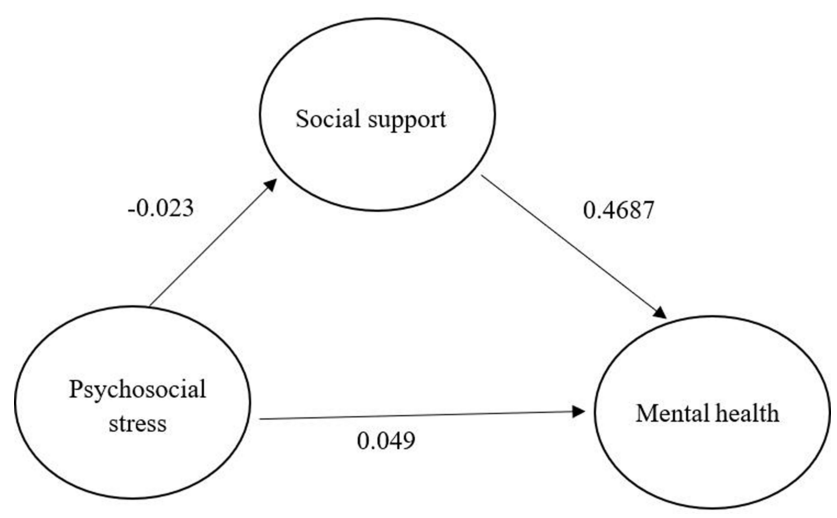

Figure 2 The mediating effect model of social support between mental health and psychosocial stress. $p<0.01)$. Finally, PSSG and SSSR total scores were used as independent variables, and SCL-90-R total score was used as a dependent variable for regression analysis. The effects of psychosocial stress and social support on mental health are significant. Social support plays a partial mediating role in reservoir migrants mental health and psychosocial stress. When the mediating effect is significant, researchers are more concerned with the amount of effect, that is, the size of the mediating effect. The most widely used method for calculating the mediating effect is $a b / c$, where $c$ is the total effect of $\mathrm{X}$ on $\mathrm{Y}$ (it is 0.049 ), and $a b$ is the mediating effect of the intermediate variable $M$ (it is $0.193 \times 0.119$ ). Therefore, the ratio of the mediating effect to the total effect was $0.193 \times 0.119 / 0.049=46.87 \%$. As a partial intermediary variable, social support indirectly affects the relationship between SNWDP migrant's mental health and psychosocial stress. The results of mediating effect shown in Table 3 and Figure 2.

\section{Discussion}

To our knowledge, this study was the first cross-sectional study to examine the relationship between mental health, psychosocial stress, and social support among SNWDP migrants. We revealed that the SNWDP migrants' mental health, psychosocial stress and social support are closely related. The most important finding was that social support played a partial mediating role in mental health and psychosocial stress. 
Our study showed that the SCL-90-R was 1.47, which was higher than both the total score of the SCL-90-R for the China Three Gorges Project migrants and the Chinese residents' normal score. ${ }^{28,29}$ Currently, there are two different theories about the mental health consequences of migrants. One is about "intercultural stress", and the other addressing "healthy migrant effect". The former views believed that relocation was the process that involved multiple stressors. A study of international migration reports that Latino immigrants with high rates of anxiety, stress, and depressive symptoms. ${ }^{30}$ Demand for mental health services might be increased among migrants, but their use of mental health services was inadequate and access to help was delayed. ${ }^{31}$ The latter refers to the health benefits of migrants, ie, migrants strong enough to withstand the rigor of relocation, whose health might be better than that of the native population, including reduced mortality, reduced chronic disease and disability, and lower mental health problems. ${ }^{32,33}$ The SNWDP migration resettlement policy tends to allopatric relocation, meaning that the migrants have to reconstruct their social networks. In China, it was viewed as a way to revitalise migration communities. Meanwhile, economic and employment factors are crucial to the lives of rural migrants. ${ }^{34}$ However, SNWDP migrants may show willingness to work in jobs that are less desirable, owing to lower levels of education and lack of social support. We found that $70.06 \%$ of SNWDP migrants were engaged in agricultural working and income satisfaction might be limited in these jobs. When migrants enter the urban Labour market, they have lower skills, resulting in wage inequality. Further, increase in left-behind elderly migrants caused by the process of urbanization in China. In addition, given to the conservative awareness of the new environment, loneliness and the dilemma of finding a partner are quite common among SNWDP migrants who reconstruct their social networks. These might explain why the mental health of migrants from the SNWDP was higher than that of other regions. In this study, the PSSG total score was higher than the results of the Three Gorges Project migrants, but the SSRS total score was lower than New-Generation migrant workers, China. ${ }^{35,36}$ This might be related to the geographical location of migrants. Unlike immigrants, relocation is a major life event which invariably involves changes in socioeconomic status (SES), lifestyle, and environment for SNWDP migrants. SNWDP migrants living environment has changed and the decrease of living resources resulting in psychosocial stress.
Hashemi et al found that the social support of immigrants stems from their interdependent collective culture, which emphasizes the role of family, friends, neighbors and communities. ${ }^{37}$ The complexity and severity of the challenges faced by migrants before and after relocation, lacking social support have been identified as the main obstacle to migrants. ${ }^{38}$ Given the differences in living habits and social networks, SNWDP migrants difficult integrated into local social circles and got less social support. Previous studies have reported that social support was associated with mental health, as well as cardiovascular, neuroendocrine and immune system changes. ${ }^{39} \mathrm{We}$ found that social support has an indirect impact on mental health through psychosocial stress. This outcome further validates the conclusions of the relevant analysis: the higher the level of social support for SNWDP migrants is, the better their mental health and psychosocial stress levels are. The effect of social support was depended mainly on the reliability and extensiveness of social network relationships. The more social support the SNWDP migrants receive, the better their integration into society and the better their mental health. Owing to the mental health and psychosocial stress of migrations are affected by many factors, such as individual factors and socioeconomic factors, they are complex and diverse. ${ }^{40,41}$ Social support was only one of the influencing factors. Therefore, the total effect ratio of social mediation in this study was not high and had only a partial effect (46.87\%).

In general, the relationship between migration mental health and psychosocial stress is more complicated. We only examined the mediating role of social support between the two variables, and further studies should be conducted on the mediating role of other variables. Additionally, the mental health of this study is mainly focused on the selfjudgement of SNWDP migrants, but some people adopt a cover-up or avoidance attitude towards their mental health problems; thus, future studies should be looked at adopting diversified methods to reduce such errors.

\section{Strengths and Limitations}

Our study had a few strengths as follows: First, this is the first study of the correlation between SNWDP migrants' mental health, psychosocial stress and social support. Second, we found that the mediating role of SNWDP migrants' social support in psychosocial stress and mental health. Third, our results have important value for developing policies to improve SNWDP migrants' mental health and social support. However, we should be acknowledged the limitations in this 
study. First, the cross-sectional design of the study limits any causal inferences between the variables of interest. Second, non-immigrants were not included for comparison. In addition, our sample was only from a few cities in China, and might not be representative of all SNWDP migrants.

\section{Conclusion}

This study showed that SNWDP migrants' social support was related to mental health and psychosocial stress, social support played a part in mediating the two variables. Owing to the complexity of the factors affecting the mental health of migrants, further study should be conducted on the relationship between migrants' mental health, psychosocial stress and social support.

\section{Acknowledgments}

We acknowledge the Hubei Provincial Department of Education for providing this project with data collection from the migration Bureau.

\section{Author Contributions}

All authors made substantial contributions to conception and design, acquisition of data, or analysis and interpretation of data; took part in drafting the article or revising it critically for important intellectual content; gave final approval of the version to be published; and agree to be accountable for all aspects of the work. These authors contributed equally in the study: Pan $\mathrm{Ke}$ and $\mathrm{Li} \mathrm{Ke}$. These authors are co-corresponding authors: Bing Liu and Xiang Liu.

\section{Funding}

The study was supported by a grant from the Hubei Provincial Department of Education Philosophy and Social Science Research Project (16ZD028).

\section{Disclosure}

The authors declare no conflicts of interest for this study.

\section{References}

1. Awumbila. World Migration Report 2015; 2015. Available from: https://www.iom.int/wmr/2015. Accessed January 19, 2021.

2. Xiao Y, Wang Z, Li Z, et al. An assessment of urban park access in Shanghai - Implications for the social equity in urban China. Landsc Urban Plan. 2016;157(1):383-393. doi:10.1016/j.landurbplan.20 16.08.007

3. Fei L, Jiandong J. A study on water conservancy project migration planning from the perspective of urban-rural relationship. Yangtze River Tech Econ. 2020;(1):69-75. doi:10.19679/J
4. Duanying C, Mengqi X, Lu H, Ziyue C, Sijie J. Posttraumatic growth of migrants on the middle route of South-to-North Water Diversion Project and its influencing factors. Chin Soc Med. 2020;1 (4):378-380.

5. Mola CLD, Stanojevic S, Ruiz P, et al. The effect of rural-to-urban migration on social capital and common mental disorders: PERU MIGRANT study. Soc Psych Psych Epid. 2012;47(6):967-973. doi:10.1007/s00127-011-0404-6

6. Stillman S, Mckenzie D, Gibson J. Migration and mental health: evidence from a natural experiment. J Health Econ. 2009;28 (3):677-687.

7. Health TL. No public health without migrant health. Lancet Public Health. 2018. doi:10.1016/S2468-2667(18)30101-4

8. Torres JM, Wallace SP. Migration circumstances, psychological distress, and self-rated physical health for Latino immigrants in the United States. Am J Public Health. 2013;103(9):1619-1627. doi:10.2105/AJPH.2012.301195

9. Derr AS. Mental health service use among immigrants in the united states: a systematic review. Psychol Serv. 2015;67(3):appips 201500004. doi:10.1176/appi.ps.201500004

10. Nørredam M. Migration and health: exploring the role of migrant status through register-based studies. Dan Med J. 2015;62(4):B5068. doi:10.1155/2012/621914

11. Teunissen E, Sherally J, van den Muijsenbergh M, et al. Mental health problems of undocumented migrants (UMs) in The Netherlands: a qualitative exploration of help-seeking behaviour and experiences with primary care. BMJ Open. 2014;4(11): e005738. doi:10.1136/bmjopen-2014-005738

12. Nap A, van Loon A, Peen J, et al. influence of acculturation on mental health and specialized mental healthcare for non-western migrants. Int J Soc Psychiatry. 2015;61(6):530-538. doi:10.1177/ 0020764014561307

13. Anikeeva O, Bi P, Hiller JE, Ryan P, Roder D, Han G-S. The health status of migrants in Australia: a review. Asia Pac J Public Health. 2010;22(2):159-193. doi:10.1177/1010539509358193

14. Dan X, Guoqin Z, Caihong S, Qingfeng T. Psychosocial stress status and influencing factors of immigrants in Danjiangkou reservoir area during the transition period. Chine Public Health. 2017;1 (5):834-837.

15. Tilahun M, Workicho A, Angaw DA. Common mental disorders and its associated factors and mental health care services for Ethiopian labour migrants returned from Middle East countries in Addis Ababa, Ethiopia. BMC Health Serv Res. 2020;20(1):681. doi:10.1186/ s12913-020-05502-0

16. Ma S, Li Q, Zhou X, et al. Assessment of health inequality between urban-to-urban and rural-to-urban migrant older adults in China: a cross-sectional study. BMC Public Health. 2020;20(1):268. doi:10.1186/s12889-020-8341-5

17. Washington TD. Psychological stress and anxiety in middle to late childhood and early adolescence: manifestations and management. J Pediatr Nurs. 2009;24(4):302-313. doi:10.1016/j.pedn.2008.04.011

18. Matsue RY. "Being home away from home": vulnerability, religiosity and social support among Brazilian migrants in Japan. Cien Saude Colet. 2012;17(5):1135-1142. doi:10.1590/s141381232012000500007

19. Muñoz-Bermejo L, Adsuar JC, Postigo-Mota S, et al. Relationship of perceived social support with mental health in older caregivers. Int J Environ Res Public Health. 2020;17(11):3886. doi:10.3390/ ijerph17113886

20. Baldassar L, Wilding R. Migration, aging, and digital kinning: the role of distant care support networks in experiences of aging well. Gerontologist. 2020;60(2):313-321. doi:10.1093/geront/gnz156

21. Chen L, Ngoubene-Atioky AJ, Zanardelli G, et al. Abuse and suicidal behaviors among Chinese migrant workers: the mediating role of alexithymia and social support. Arch Suicide Res. 2020;24 (4):633-647. doi:10.1080/13811118.2019.1658142 
22. Long C, Wang R, Feng D, et al. Social support and health services use in people aged over 65 years migrating within China: a cross-sectional study. Int J Environ Res Public Health. 2020;17 (13):4651. doi:10.3390/ijerph17134651

23. Canqing Y, Jun L Related factors of generalized anxiety disorder in adults aged 30 to 79 years in 10 regions of China. Chin Mental Health J. 2015;1(8):581-586.

24. Schmitz N, Hartkamp N, Kiuse J, et al. The Symptom Check-List-90R (SCL-90-R): a German validation study. Qual Life Res. 2000;2:185-193. doi:10.1023/A:1008931926181

25. Ganjin J. A Preliminary Study on the Comprehensive Evaluation of Psychological Social Stress Factors. Chine J Behav Med Brain Sci. 1998;3:182-184.

26. Xiao-Yan HE, Xiao SY. Reliability and validity of the Chinese version of geriatric depression scale: a study in a population of Chinese rural community-dwelling elderly. Chin J Clin Psy. 2008.

27. Baron R, Kenny DA. The moderator-mediator variable distinction in social psychological research: conceptual, strategiC, and statistical considerations. J Pers Soc Psychol. 1986;6:1173-1182. doi:10.1037/ 0022-3514.51.6.1173

28. Lihui Z, Jizhi G, Yang W, et al. Mental health status and related factors of rural migrants in the Three Gorges Reservoir Area. Chin $J$ of Natur Med. 2008;1(3):183-186.

29. Huijie T. A 20-year change of the SCL-90 scale and its norm. Psychol Sci. 2010;4:928-930+921. doi:10.16719/j

30. Alarcón RD, Parekh A, Wainberg ML, et al. Hispanic immigrants in the USA: social and mental health perspectives. Lancet Psychiatry. 2016;3(9):860-870. doi:10.1016/S2215-0366(16)30101-8

31. Rousseau C, Frounfelker RL. Mental health needs and services for migrants: an overview for primary care providers. J Travel Med. 2019;26(2):tay150. doi:10.1093/jtm/tay150

32. Roura M. Unravelling migrants' health paradoxes: a transdisciplinary research agenda. J Epidemiol Commun Health. 2017;jech-2016208439. doi:10.1136/jech-2016-208439
33. Juárez SP, Ortiz-Barreda G, Agudelo-Suárez AA. Revisiting the healthy migrant paradox in perinatal health outcomes through a scoping review in a recent host country. $J$ Immigr Minor Health. 2017;19(1):205-214. doi:10.1007/s10903-015-0317-7

34. Wang S. Inching up and socio-economic differentiation: exploring self-rated health of china's rural-to-urban migrants from 2005 to 2015. Am J Health Behav. 2018;42(5):117-125. doi:10.5993/ AJHB.42.5.10

35. Wang Q, Huang B. The relationship between mental health status and psychological stress among migrants from Chongqing and Sichuan Three Gorges. J Chongqing Med Univ. 2009;2:221-223.

36. Haiyan XING, Wei YU, Sanmei CHEN. Influence of social support on health-related quality of life in new-generation migrant workers in Eastern China. Iran J Public Health. 2013;42(8):806-812.

37. Hashemi N, Marzban M, Sebar B, Harris N. Perceived discrimination and subjective well-being among Middle Eastern migrants in Australia: the moderating role of perceived social support. Inter J Soc Psych. 2020;2020. doi:10.1177/0020764020940740

38. Li Y, Wu S. Social networks and health among rural-urban migrants in China: a channel or a constraint? Health Promot Int. 2010;25 (3):371-380. doi:10.1093/heapro/daq020

39. Mookadam F, Arthur HM. Social support and its relationship to morbidity and mortality after acute myocardial infarction: systematic overview. Archives Inter Med. 2004;14:1514-1518. doi:10.1001/ archinte.164.14.1514

40. Salgado H, Castañeda SF, Talavera GA. The role of social support and acculturative stress in health-related quality of life among day laborers in Northern San Diego. J Immigr Minor Health. 2012;14 (3):379-385. doi:10.1007/s10903-011-9568-0

41. Wang B, Li X, Stanton B, Fang X. The influence of social stigma and discriminatory experience on psychological distress and quality of life among rural-to-urban migrants in China. Soc Sci Med. 2010;71 (1):84-92. doi:10.1016/j.socscimed.2010.03.021
Psychology Research and Behavior Management

\section{Publish your work in this journal}

Psychology Research and Behavior Management is an international, peer-reviewed, open access journal focusing on the science of psychology and its application in behavior management to develop improved outcomes in the clinical, educational, sports and business arenas. Specific topics covered in the journal include: Neuroscience, memory and decision making; Behavior modification and management; Clinical applications; Business and sports performance management; Social and developmental studies; Animal studies. The manuscript management system is completely online and includes a very quick and fair peer-review system, which is all easy to use. Visit http://www dovepress.com/testimonials.php to read real quotes from published authors. 